\title{
Sexual difficulties and help-seeking among mature adults in Australia: results from the Global Study of Sexual Attitudes and Behaviours
}

\author{
Edson D. Moreira Jr ${ }^{\mathrm{A}, \mathrm{E}}$, Dale B. Glasser ${ }^{\mathrm{B}}$, Rosie King ${ }^{\mathrm{C}}$, Fernanda Gross Duarte ${ }^{\mathrm{A}}$, \\ Clive Gingell ${ }^{\mathrm{P}}$ and for the GSSAB Investigators' Group ${ }^{*}$ \\ AUnit of Epidemiology and Biostatistics, Oswald Cruz Foundation, Rua Waldemar Falcão 121, Salvador, \\ Bahia 40.295-001, Brazil. \\ ${ }^{B}$ Pfizer Inc., 235 East 42nd Street, 235/4/MS5, Office 47, New York, NY 10017, USA. \\ ${ }^{\mathrm{C}}$ The University of New South Wales Sydney, Sydney, NSW 2052, Australia. \\ DBristol Urological Institute, Southmead Hospital, Litfield House, Clifton Down, Clifton, Bristol BS8 3 LS, \\ England, UK. \\ ${ }^{\mathrm{E}}$ Corresponding author. Email: edson@cpqgm.fiocruz.br
}

\begin{abstract}
Background: The Global Study of Sexual Attitudes and Behaviours was a survey of 27500 men and women in 29 countries. Here we report the sexual activity, the prevalence of sexual difficulties and related help-seeking behaviour among participants in Australia. Methods: A telephone survey was conducted in Australia in 2001-2002, with interviews based on a standardised questionnaire. A total of 1500 individuals ( 750 men and 750 women) aged 40 to 80 years completed the survey. The questionnaire covered demographic information, overall health, and sexual behaviours, attitudes and beliefs. Results: Overall, $83 \%$ of men and $74 \%$ of women had engaged in sexual intercourse during the 12 months preceding the interview, and $38 \%$ of all men and $29 \%$ of all women engaged in sexual intercourse more than once a week. Early ejaculation (23\%), erectile difficulties (21\%) and a lack of sexual interest (18\%) were the most common male sexual difficulties. The most frequently reported female sexual difficulties were: lack of sexual interest (33\%), lubrication difficulties $(26 \%)$ and an inability to reach orgasm $(25 \%)$. Older age was a significant predictor of male erectile difficulties and of lubrication difficulties in women. Only a minority of men and women had sought help for their sexual difficulty(ies) from a health professional. Conclusions: Many middle-aged and older adults in Australia report continued sexual interest and sexual activity. Several sexual difficulties are highly prevalent in this population, but those experiencing these difficulties rarely seek medical help. This may be because they do not perceive such difficulties as serious or sufficiently upsetting.
\end{abstract}

Additional keywords: epidemiology, health surveys, impotence, prevalence, sex, sexual disorders.

\section{Introduction}

During the past 10 years, many studies have investigated the prevalence of sexual disorders among middle-aged and older individuals. These studies have mainly focussed on the populations of individual developed nations, particularly in Europe $^{1-3}$ and the USA. ${ }^{4-6}$ Male erectile dysfunction (ED) and early ejaculation along with their related risk factors have been investigated most extensively, whereas there have been fewer studies that have focussed specifically on female sexual disorders. ${ }^{7,8}$

In Australia, several recent studies have reported the prevalence and correlates of sexual problems, ${ }^{9-13}$ but there is relatively little published information about the 'usual' frequency of sexual activity and the value placed on sexual relationships among older men and women. The few studies that have examined sexuality in mature adults in other developed countries have reported that sexual interest and activity persist well into older age. ${ }^{14-16}$ There are also currently no studies reporting how men or women in Australia attempt to manage or overcome their sexual problems.

The Global Study of Sexual Attitudes and Behaviours (GSSAB) was a population survey of 27500 men and women aged between 40 and 80 years in 29 countries representing many world regions. ${ }^{17}$ The GSSAB focussed on the problems of sex in later life, this choice was made to allow for some comparisons of our findings with previous surveys done in this same age range. Here we present data on sexual activity, sexual difficulties and related help-seeking behaviours among mature men and women in Australia.

\footnotetext{
* GSSAB Investigators' Group: Gerald Brock (Canada), Jacques Buvat (France), Uwe Hartmann (Germany), Sae-Chul Kim (Korea), Edward Laumann (USA), Bernard Levinson (South Africa), Ken Marumo (Japan), Alfredo Nicolosi (Italy) and Ferruh Simsek (Turkey).
} 


\section{Methods}

The GSSAB was the first large, multi-country survey to systematically study attitudes, beliefs and health in sexual relationships in middle-aged and older adults. The questionnaire used asked for information about demographics; health; relationships and general satisfaction; and individual behaviour, practices, attitudes and beliefs regarding sexuality. The data were collected using the most effective (i.e. less costly and time-consuming) survey method in each country. A randomdigit-dialling sampling design was used in Europe, Israel, North America, Brazil, Australia and New Zealand. In the Middle East and South Africa, a door-to-door protocol was used, whereas in Asian countries other than Japan, an intercept method was employed.

Computer-assisted telephone interviews (CATIs) were carried out (using exclusively a random-digit dialled sampling design) in Australia during 2001 and 2002, with the respondents being randomly selected within households by asking for the man or woman aged between 40 and 80 years of age who had had the most recent birthday (participants were interviewed by interviewers of the same gender). Women and men were sampled in equal numbers, by design and verbal consent was obtained from all study participants. They were also informed about the following issues: (1) all information obtained would be used in aggregate; (2) responses were voluntary; (3) the confidentiality and the privacy of their responses were protected because no personal identifiers were coded into the interview instruments; (4) no list of respondents was retained; (5) the protocol was approved by a institutional review board; and (6) 'refusers' were not called back in an effort to convert them to participating respondents.

A structured questionnaire requested information concerning general health, demographics, relationships, and sexual behaviours, attitudes and beliefs. The participants were asked if they had engaged in sexual intercourse (defined as any intimate behaviour including: penile-vaginal/anal intercourse, oral contact with genitals/breasts/nipples, or touching yours/ other's genitals) during the previous 12 months and the presence of sexual difficulties was assessed by means of two sequential questions. ${ }^{5,18}$ The respondents were first asked whether they had experienced one or more of the sexual difficulties listed in Appendix 1 for a period of at least 2 months during the previous year, and those who answered 'Yes' were then asked whether they had experienced the difficulty 'occasionally', 'sometimes' or 'frequently'.

Logistic regression was used to perform a multivariate analysis investigating potential factors associated with selected sexual dysfunction. In these analyses, the presence of a sexual problem was coded only for those respondents who reported experiencing the difficulty frequently or sometimes, whereas those who indicated that they experienced the difficulty only occasionally were recoded to indicate no sexual problem.

The participants who reported that they had experienced a sexual difficulty were asked whether they had sought help from several possible sources. Respondents could indicate that they had sought help from more than one source.

The individuals with sexual difficulties who had not consulted a physician were asked why they had not done so, and offered a list of 14 possible reasons (from which they were to indicate all that applied). The reasons included attitudes and beliefs regarding the sexual difficulty and the patient-doctor relationship. All respondents (irrespective of whether they reported any sexual difficulties) were also asked 'During a routine office visit or consultation in the past 3 years, has your physician asked you about possible sexual difficulties without you bringing it up first?' (Yes/No) and 'Do you think a doctor should routinely ask patients about their sexual function?' (Yes/No).

The prevalence of a specific characteristic was calculated by dividing the number of cases by the corresponding population. The denominator for the calculation of the prevalence of sexual difficulty was the number of sexually active people (i.e. at least one episode of intercourse during the previous 12 months). The prevalence of selected demographic characteristics and the estimates of sexual difficulties were age-standardised using the age distribution of the year 2000 population of Australia by gender, and are given with their confidence intervals (CI). ${ }^{19}$ The prevalences of help-seeking behaviours and attitudes about diagnosis of and treatment for sexual difficulties were age-adjusted according to the number of sexually active men and women in the sample.

\section{Results}

\section{Characteristics of study population}

Overall, 14986 individuals were contacted, and out of 8875 eligible participants, 1500 individuals $(750 \mathrm{men}$ and 750 women) completed the survey, for a response rate of $16.9 \%$. Table 1 presents selected characteristics of the study sample. The majority of the male $(66.4 \%)$ and female $(65.9 \%)$ respondents were married or involved in an ongoing partnership (Table 1). Employment rates among men and women were $65.3 \%$ and $55.7 \%$, respectively, and $80 \%$ of men $(80.3 \%)$ and women $(80.4 \%)$ reported that they were in good or excellent general health.

The percentage of individuals who were sexually active significantly decreased with age in both gender $(P<0.001)$. Although there was a progressive decrease in sexual activity with age, a larger drop was observed in both men and women in the 70 to 80 years of age. Although $83.2 \%$ of men and $73.5 \%$ of women out of all the participants in the study said that they had had sexual intercourse during the 12 months preceding the interview, only $\sim 38.1 \%$ of men and $29.1 \%$ of women reported that they engaged in sexual intercourse more than once a week.

\section{Prevalence of sexual difficulties}

Early ejaculation (23.3\%) was the most common reported sexual difficulty among sexually active men in Australia and approximately two-thirds of the men with this difficulty said that they experienced it sometimes or frequently (Table 2). Erectile difficulty (21.1\%) was the second most common male sexual difficulty in the Australian sample, followed by a lack of sexual interest $(17.5 \%)$. The majority of the men who reported these difficulties said that they 
Table 1. Selected characteristics of the study population, Australia, 2001-2002 (percentage; age-standardised prevalence)

*Self-reported 'good' or 'excellent' general health ( $v$. 'fair' or 'poor')

\begin{tabular}{|c|c|c|}
\hline & $\begin{array}{c}\text { Men } \\
(n=750)\end{array}$ & $\begin{array}{c}\text { Women } \\
(n=750)\end{array}$ \\
\hline \multicolumn{3}{|l|}{ Age group (years) } \\
\hline $40-49$ & 39.4 & 40.0 \\
\hline $50-59$ & 29.9 & 31.9 \\
\hline $60-69$ & 18.6 & 17.6 \\
\hline $70-80$ & 12.1 & 10.5 \\
\hline \multicolumn{3}{|l|}{ Relationship status } \\
\hline Married or ongoing partnership & 66.4 & 65.9 \\
\hline Divorced/separated without sex partner & 19.0 & 18.5 \\
\hline Widowed without sex partner & 5.0 & 12.1 \\
\hline Single without sex partner & 9.7 & 3.5 \\
\hline Urban/suburban residential setting & 69.5 & 71.0 \\
\hline \multicolumn{3}{|l|}{ Education } \\
\hline Primary school or less & 32.3 & 30.2 \\
\hline Secondary/high school & 44.0 & 49.1 \\
\hline At least some college & 23.8 & 20.7 \\
\hline \multicolumn{3}{|l|}{ Household income } \\
\hline Low (less than USD\$20 000 per year) & 33.6 & 39.6 \\
\hline Medium (USD\$20000 to 30000 per year) & 25.8 & 25.8 \\
\hline High (more than USD\$30 000 per year) & 40.6 & 34.6 \\
\hline Currently employed & 65.3 & 55.7 \\
\hline \multicolumn{3}{|l|}{ Religion } \\
\hline Christian & 75.0 & 85.0 \\
\hline Jew & 0.3 & 0.4 \\
\hline Atheist & 1.8 & 0.6 \\
\hline Not specified & 22.4 & 13.9 \\
\hline Good to excellent general health* & 80.3 & 80.4 \\
\hline Intercourse in the past 12 months & 83.2 & 73.5 \\
\hline $40-49$ & 93.6 & 90.2 \\
\hline $50-59$ & 85.7 & 77.9 \\
\hline $60-69$ & 79.1 & 57.3 \\
\hline $70-80$ & 48.9 & 24.4 \\
\hline Intercourse more than once a week & 38.1 & 29.1 \\
\hline
\end{tabular}

experienced them sometimes or frequently. The other sexual difficulties were experienced less frequently.

Among sexually active women in Australia, a lack of sexual interest $(32.8 \%)$ was the most common sexual difficulty, followed by difficulty becoming adequately lubricated $(26.4 \%)$ and an inability to reach orgasm $(24.9 \%)$ (Table 2). The majority of the women who reported each of these difficulties said that they experienced it frequently or sometimes. The other sexual difficulties investigated were experienced somewhat less frequently. Overall, lack of sexual interest, inability to reach orgasm, finding sex not pleasurable, and experiencing pain during sex were significantly more prevalent among women than men (all $P$-values $<0.001$ ).

Demographic, socioeconomic, physical and health factors associated with three selected sexual problems in men and women were investigated (odds ratios [OR] from logistic regression). Older age (compared with the referent age of 40 to 49 years) was a significant correlate of erectile difficulties in men; at age 50 to 59 years the OR was 2.02 $(95 \%$ CI $1.02-4.01 ; P \leq 0.05)$ and at 60 to 80 years the OR
Table 2. Age-standardised prevalence of sexual problems in men and women in Australia by severity, 2001-2002

Note: based on reports from sexually active respondents. Percentage in the first row of each panel indicates the country average of sexual problem, defined as an experience of problem for a period of 2 months or more. The difference between the country average and the sum of the three levels of severity of sexual problem indicates the proportion who failed to specify the level of severity

\begin{tabular}{|c|c|c|}
\hline & $\begin{array}{c}\% \text { Men }(95 \% \\
\text { confidence interval) }\end{array}$ & $\begin{array}{c}\% \text { Women }(95 \% \\
\text { confidence interval) }\end{array}$ \\
\hline Early ejaculation & $23.3(22.7,24.0)$ & - \\
\hline Occasional & $7.7(6.9,8.5)$ & - \\
\hline Sometimes & $10.0(9.2,10.8)$ & - \\
\hline Frequent & $5.7(5.0,6.5)$ & - \\
\hline Erectile difficulties & $21.1(20.4,21.9)$ & - \\
\hline Occasional & $6.0(5.3,6.9)$ & - \\
\hline Sometimes & $8.5(7.7,9.4)$ & - \\
\hline Frequent & $6.6(5.8,7.5)$ & - \\
\hline $\begin{array}{l}\text { Lack of sexual } \\
\text { interest }\end{array}$ & $17.5(16.8,18.5)$ & $32.8(32.1,33.5)$ \\
\hline Occasional & $6.7(5.9,7.5)$ & $9.7(8.9,10.6)$ \\
\hline Sometimes & $6.6(5.8,7.4)$ & $14.1(13.3,14.9)$ \\
\hline Frequent & $4.3(3.5,5.2)$ & $9.0(8.3,9.9)$ \\
\hline $\begin{array}{l}\text { Inability to reach } \\
\text { orgasm }\end{array}$ & $13.9(13.1,14.6)$ & $24.9(24.2,25.7)$ \\
\hline Occasional & $6.4(5.7,7.3)$ & $8.5(7.6,9.3)$ \\
\hline Sometimes & $4.5(3.7,5.4)$ & $12.4(11.7,13.3)$ \\
\hline Frequent & $2.9(2.1,4.0)$ & $4.0(3.2,4.9)$ \\
\hline Sex not pleasurable & $8.1(7.3,8.9)$ & $18.2(17.5,19.0)$ \\
\hline Occasional & $2.8(2.1,3.7)$ & $5.6(4.8,6.5)$ \\
\hline Sometimes & $3.3(2.6,4.1)$ & $9.0(8.2,9.9)$ \\
\hline Frequent & $2.0(1.2,3.1)$ & $3.6(2.8,4.5)$ \\
\hline Pain during sex & $2.7(2.0,3.6)$ & $8.7(8.0,9.5)$ \\
\hline Occasional & $2.1(1.4,3.2)$ & $2.8(2.1,3.7)$ \\
\hline Sometimes & $0.6(0.1,1.8)$ & $3.9(3.2,4.8)$ \\
\hline Frequent & $0.0(0.0,0.0)$ & $2.0(1.3,3.0)$ \\
\hline Lubrication difficulties & - & $26.4(25.7,27.2)$ \\
\hline Occasional & - & $4.4(3.6,5.3)$ \\
\hline Sometimes & - & $12.4(11.6,13.2)$ \\
\hline Frequent & - & $9.7(8.9,10.5)$ \\
\hline
\end{tabular}

was $4.30(95 \%$ CI $2.16-8.56 ; P \leq 0.001)$. Among women, the age range of 50 to 59 years was associated with increased likelihood of lubrication difficulties (OR 1.98, 95\% CI $1.24-3.16 ; P \leq 0.001)$, whereas the age range of 60 to 80 years was associated with a significantly reduced likelihood of experiencing an inability to reach orgasm in women (OR 0.45, 95\% CI 0.21-0.97; P $\leq 0.05$ ), compared with the referent age range of 40 to 49 years. A lower than average level of physical activity was a significant correlate of erectile difficulties in men (OR 2.50, 95\% CI 1.26-4.97; $P \leq 0.01$ ), and a medium or high (compared with low) household income was a significant correlate of an increased risk of lubrication difficulties among women (OR 1.69, 95\% CI $1.01-2.82 ; P \leq 0.05)$ and a decreased risk of lack of sexual interest in men (OR $0.55,95 \%$ CI $0.31-0.97 ; P \leq 0.05$ ). The impact of a diagnosis of several common health conditions was 
Table 3. Prevalence of selected help seeking behaviours for sexual problems in Australia, by gender, 2001-2002

Note: based on reports from sexually active respondents complaining of at least one sexual problem

\begin{tabular}{|c|c|}
\hline & $\begin{array}{l}\% \text { ( } 95 \% \text { confidence } \\
\text { interval) }\end{array}$ \\
\hline \multicolumn{2}{|l|}{ Men } \\
\hline Talked to partner & $37.1(36.2,38.0)$ \\
\hline Talked to medical doctor & $21.4(20.4,22.4)$ \\
\hline $\begin{array}{l}\text { Taken drugs/used devices } \\
\text { or talked to pharmacist }\end{array}$ & $13.0(12.0,14.1)$ \\
\hline $\begin{array}{l}\text { Looked for information anonymously } \\
\text { (in books/magazines or via } \\
\text { telephone help-line/internet) }\end{array}$ & $11.3(10.3,12.4)$ \\
\hline Talked to family member/friend & $4.4(3.3,5.6)$ \\
\hline $\begin{array}{l}\text { Talked to psychiatrist, psychologist or } \\
\text { marriage counsellor }\end{array}$ & $2.1(1.2,3.7)$ \\
\hline $\begin{array}{l}\text { Talked to a clergy person or religious } \\
\text { adviser }\end{array}$ & $0.3(0.0,3.6)$ \\
\hline Sought no help from a health professional & $77.6(77.0,78.1)$ \\
\hline No action taken & $50.0(49.2,50.8)$ \\
\hline \multicolumn{2}{|l|}{ Women } \\
\hline Talked to partner & $37.2(36.4,38.0)$ \\
\hline Talked to medical doctor & $20.2(19.3,21.1)$ \\
\hline $\begin{array}{l}\text { Looked for information anonymously } \\
\text { (in books/magazines or via telephone } \\
\text { help-line/internet) }\end{array}$ & $13.1(12.2,14.0)$ \\
\hline $\begin{array}{l}\text { Taken drugs/used devices or talked to } \\
\text { pharmacist }\end{array}$ & $11.8(11.0,12.8)$ \\
\hline Talked to family member/friend & $11.0(10.1,12.0)$ \\
\hline $\begin{array}{l}\text { Talked to psychiatrist, psychologist or } \\
\text { marriage counsellor }\end{array}$ & $3.0(2.0,4.1)$ \\
\hline Talked to a clergy person or religious adviser & $0.3(0.0,3.9)$ \\
\hline Sought no help from a health professional & $76.6(76.1,77.1)$ \\
\hline No action taken & $49.9(49.1,50.7)$ \\
\hline
\end{tabular}

investigated, and it was observed that depression was a significant correlate of a lack of sexual interest (OR 2.28, 95\% CI $1.47-3.53 ; P \leq 0.001)$ and lubrication difficulties (OR 1.89, 95\% CI 1.15-3.11; $P \leq 0.01$ ) in women; diabetes was a significant correlate of male erectile difficulties (OR 2.33, 95\% CI 1.10-4.90; $P \leq 0.05)$.

\section{Help-seeking behaviour}

The prevalence of selected help-seeking behaviours for sexual difficulties among men and women in Australia is summarised in Table 3. Of the sexually active respondents who reported experiencing at least one sexual difficulty, $50.0 \%$ of men and $49.9 \%$ of women had not taken any action. Patterns of helpseeking behaviours were remarkably similar among men and women in Australia and talking to their partner was the most common action, reported by $37.1 \%$ of men and $37.2 \%$ of women. More women than men had talked to a family member or friend $(11.0 \%$ v. $4.4 \%, P=0.001)$, whereas very few respondents of either gender had talked to a psychiatrist, psychologist or marriage counsellor $(2.1 \%$ of men and $3.0 \%$ of women) or to a member of the clergy or other religious adviser ( $0.3 \%$ men and women). Only $21.4 \%$ of men and $20.2 \%$ of women said that they had talked to a medical doctor about their sexual difficulty(ies), and $13.0 \%$ of men and $11.8 \%$ of women had talked to a pharmacist or had used drugs or devices, but the majority of men $(77.6 \%)$ and women $(76.6 \%)$ had sought no help from a health professional.

\section{Factors associated with seeking medical help for sexual difficulties}

Some factors that might be associated with seeking medical help for sexual difficulties were investigated using logistic regression. A significant effect of age was seen in men, compared with the referent group which was aged 40 to 49 years, at age 60 to 69 years the OR was 5.80 (95\% CI 1.78-18.84; $P \leq 0.001)$ and at 70 to 80 years the OR was 4.58 (95\% CI $1.17-18.02$; $P \leq 0.05$ ). Erectile difficulties in men (OR 5.32, 95\% CI 2.27-12.48; $P \leq 0.001)$ and lubrication difficulties in women (OR 2.80, 95\% CI 1.48-5.33; $P \leq 0.001$ ) were significant correlates of seeking medical help for sexual difficulties. Interestingly, among women, having a medium or high (compared with low) household income was a significant negative correlate of seeking medical help for sexual difficulties. Several sexual beliefs and attitudes were significantly correlated with seeking medical help for sexual difficulties. These were: among both men and women, having been asked by a doctor about possible sexual difficulties during a routine visit in the past 3 years (OR 8.37 and 5.92, respectively); among men only, being very or somewhat dissatisfied with own sexual functioning (OR 2.99, 95\% CI 1.22-7.32; $P \leq 0.05$ ) and a belief that decreased sexual ability would significantly affect own self-esteem (OR 3.66, 95\% CI 1.47-9.09; $P \leq 0.01$ ); and among women only, a belief that sex is a very or extremely important part of overall life (OR 2.21, 95\% CI $1.09-4.49 ; P \leq 0.05)$.

\section{Attitudes and beliefs about diagnosis and treatment of sexual difficulties}

The reasons for not consulting a doctor about a sexual difficulty that were cited most frequently by respondents in Australia were thinking it is not very serious or waiting for the difficulty to go away (50.0\% of men and $54.1 \%$ of women) and believing that it is a normal part of aging or being comfortable as he/she is (48.7\% of men and $44.9 \%$ of women) (Table 4 ). Somewhat fewer men and women cited thinking that it is not a medical difficulty or that a doctor could not do much about it $(26.4 \%$ of men and $20.7 \%$ of women) and even fewer cited embarrassment about discussing sexual difficulties with their medical doctor (11.9\% of men and $8.3 \%$ of women). Lack of access to or affordability of medical care were cited as reasons by only $5.6 \%$ of men and $3.0 \%$ of women. Very few respondents in Australia had been asked by a doctor about possible sexual difficulties during a routine visit in the past 3 years $(6.5 \%$ of men and $5.8 \%$ of women) but $\sim 40 \%$ of men $(46.8 \%)$ and women $(39.0 \%)$ thought that a doctor should routinely ask patients about their sexual function.

\section{Discussion}

The present study reports population-level data on sexual behaviour, the prevalence of sexual difficulties and associated help-seeking behaviours among middle-aged and older adults in Australia, being the first to do so for the 60 to 80 year age group. 
Table 4. Attitudes, behaviours and beliefs about diagnosis of and treatment for sexual problem in Australia, by gender, 2001-2002

\begin{tabular}{|c|c|}
\hline & $\begin{array}{l}\%(95 \% \text { confidence } \\
\text { interval })\end{array}$ \\
\hline \multicolumn{2}{|l|}{ Men } \\
\hline \multicolumn{2}{|l|}{$\begin{array}{l}\text { Reasons for not consulting a doctor about } \\
\text { the experienced sexual problem }\end{array}$} \\
\hline $\begin{array}{l}\text { Did not think it was very serious/waiting } \\
\text { if problem goes away }\end{array}$ & $50.0(49.1,50.9)$ \\
\hline $\begin{array}{l}\text { Normal with aging/I am comfortable the } \\
\text { way I am }\end{array}$ & $48.7(47.8,49.6)$ \\
\hline $\begin{array}{l}\text { Doctor cannot do much/do not think it is a } \\
\text { medical problem }\end{array}$ & $26.4(25.3,27.5)$ \\
\hline $\begin{array}{l}\text { Not comfortable talking to a doctor/doctor } \\
\text { is a close friend/doctor is the wrong gender }\end{array}$ & $11.9(10.7,13.1)$ \\
\hline $\begin{array}{l}\text { Do not have a regular physician/doctor is } \\
\text { expensive }\end{array}$ & $5.6(4.4,7.0)$ \\
\hline Doctor uneasy to talk about sex & $3.0(1.9,4.5)$ \\
\hline $\begin{array}{l}\text { Have been asked by a doctor about possible } \\
\text { sexual difficulties in a routine visit in the } \\
\text { past } 3 \text { years }{ }^{B}\end{array}$ & $6.5(5.8,7.2)$ \\
\hline $\begin{array}{l}\text { Think a doctor should routinely ask patients } \\
\text { about their sexual function }{ }^{\mathrm{B}}\end{array}$ & $46.8(46.3,47.3)$ \\
\hline \multicolumn{2}{|l|}{ Women } \\
\hline \multicolumn{2}{|l|}{$\begin{array}{l}\text { Reasons for not consulting a doctor about the } \\
\text { experienced sexual problem }\end{array}$} \\
\hline $\begin{array}{l}\text { Did not think it was very serious/waiting if } \\
\text { problem goes away }\end{array}$ & $54.1(53.3,54.9)$ \\
\hline $\begin{array}{l}\text { Normal with aging } / \mathrm{I} \text { am comfortable the } \\
\text { way I am }\end{array}$ & $44.9(44.0,45.8)$ \\
\hline $\begin{array}{l}\text { Doctor cannot do much/do not think it is a } \\
\text { medical problem }\end{array}$ & $20.7(19.7,21.8)$ \\
\hline $\begin{array}{l}\text { Not comfortable talking to a doctor/doctor is a } \\
\text { close friend/doctor is the wrong gender } \\
\text { is the wrong gender }\end{array}$ & $8.3(7.3,9.4)$ \\
\hline $\begin{array}{l}\text { Do not have a regular physician/doctor is } \\
\text { expensive }\end{array}$ & $3.0(2.0,4.3)$ \\
\hline Doctor uneasy to talk about sex & $1.3(0.4,2.9)$ \\
\hline $\begin{array}{l}\text { Have been asked by a doctor about } \\
\text { possible sexual difficulties in a routine visit } \\
\text { in the past three years }{ }^{\mathrm{B}}\end{array}$ & $5.8(5.1,6.6)$ \\
\hline $\begin{array}{l}\text { Think a doctor should routinely ask patients } \\
\text { about their sexual function }{ }^{\mathrm{B}}\end{array}$ & $39.0(38.5,39.6)$ \\
\hline $\begin{array}{l}{ }^{\mathrm{A}} \text { Based on reports from sexually active respondent } \\
\text { least one sexual problem who have not consulted } \\
{ }^{\mathrm{B} B} \text { Based on all respondents. All prevalences are adjus } \\
\text { age distribution of the total of sexually active me } \\
\text { Australia in this sample. }\end{array}$ & $\begin{array}{l}\text { omplaining of at } \\
\text { doctor. } \\
\text { according to the } \\
\text { and women in }\end{array}$ \\
\hline
\end{tabular}

Face-to-face interviews were not used because they may cause excessive embarrassment when individuals are asked to provide information about private and sensitive matters, and may also increase the likelihood that respondents will feel obliged to give 'socially desirable' answers. ${ }^{20}$ Only sexual difficulties that persisted with moderate to higher frequency were considered to be 'sexual problems'. ${ }^{21}$ This approach minimises the risk of false-positive responses. It does mean, however, that the prevalence of sexual problem may have been under-reported in our survey in comparison with studies that used more sensitive, but less specific, methods. The presence of sexually related personal distress was not measured in our survey and represents a limitation of our study, since such assessment is prerequisite for a diagnosis of female sexual dysfunction according to the American Psychiatric Association.

When estimating the prevalence of sexual difficulties, we have only included individuals who are sexually active. Individuals with sexual difficulties may cease being sexually active as a consequence of sexual difficulties, this may have underestimated our prevalence estimates. Our findings were similar to those reported by Najman et al. ${ }^{10}$ in the age category (40 to 59 years). The prevalence of lack of interest in having sex was $14.5-17.0 \%$ among men in our study $v$. $14-16 \%$ in their survey, and $28-39 \%$ v. 34-35\% among women, respectively. Erectile difficulties $(10-18 \%$ v. 8-20\%) in men and lubrication difficulties in women $(21-34 \%$ v. $23-33 \%)$ were also reported in similar frequencies in both studies. But inability to reach orgasm was more prevalent among both men $(9-12 \% \mathrm{v}$. $5-9 \%)$ and women $(19-36 \%$ v. 17-26\%) in our sample as compared with participants enrolled in Najman and colleague's study. ${ }^{10}$

Some estimates in the present study, however, are quite different from those of other similar Australian study, where Richters et $a l .{ }^{11}$ reported a prevalence of pain during sex of between $15.2 \%$ to $18.0 \%$ (women age $40-59$ ), compared with $8.7 \%$ (women over 40) in our study. They also found a prevalence of lack of sexual interested of $56.5 \%$ to $60.9 \%$ (women age 40-59) compared with 32.8\% (women over 40) in the present study. Although the above differences may be real, they may also result from the different age distribution of study individuals or other distinctions between the participants in each study. However, we cannot rule out that response bias in our survey might have played a role in the genesis of these discrepancies.

The overall response rate in Australia (16.9\%) was quite low. Although it is true that low completion rates can serve as a flag for the possibility of systematic biases in sample coverage, it by no means guarantees or necessitates it. It is well known, that people are in general highly resistant to telephone interviewing and are likely to decline to participate; regardless of the subject matter (especially if no callbacks are allowed, as in our survey). Systematic bias in response that is tied in unknown ways to the variables of interest is the key concern. The prevalence of selfreported health conditions such as diabetes (7.5\%), smoking (21\%) and depression (15\%) in our study was comparable with published values, $8 \%, 23 \%$ and $17 \%$, respectively. ${ }^{22-25}$ This suggests that the study population was broadly representative of the general population. However, some of our findings differ from those of previous Australian studies and we cannot exclude the possibility that the low response rate may have introduced bias into our results.

A diagnosis of diabetes was a significant correlate of ED in our study. Several studies have shown ED to be more prevalent in diabetic individuals, which of the several aspects of diabetes is the direct causative agent of ED is controversial. Vascular disease, autonomic neuropathy, gonadal dysfunction, and vascular endothelium or neurogenic impairment of penile smooth muscle relaxation are frequently mentioned. In 
addition, possible treatment side effects have also been implicated. $^{26}$

Increasing age and a lower-than-average level of physical activity were also significant correlates of ED in our study. These findings are consistent with earlier studies of sexual difficulties in Australia, which have also shown that the prevalence of ED increases with age $\mathrm{e}^{9-11}$ and that a history of vigorous exercise is protective against ED across all age groups. ${ }^{9}$ Increasing age appears to have less consistent effects in women in our sample; however, as the age range of 50 to 59 years was significantly associated with lubrication difficulties (compared with the referent group aged 40 to 49 years), the oldest age range of 60 to 80 years was negatively correlated with an inability to reach orgasm. The age range of 50 to 59 years is significant for women as it is the age at which many may experience menopause. A decline in female sexual functioning, including a significant increase in vaginal dryness during the menopausal transition has been observed previously in the Melbourne Women's Midlife Health Project. ${ }^{27}$

A diagnosis of depression was a significant correlate of a lack of sexual interest and lubrication difficulties in women in Australia but, interestingly, the condition showed no significant correlation with any of the selected male sexual problems. When considering the co-presence of depression and sexual problem, the possible role of antidepressant treatments must also be taken into account. Sexual dysfunction is a frequent adverse effect of antidepressant therapy; however, the reported rates of dysfunction vary according to the treatment used..$^{28-30}$ The selective serotonin reuptake inhibitors (SSRI) appear to be associated with particularly high rates of sexual dysfunction and although men taking SSRI report higher rates of sexual side effects than women, women seem to experience more severe dysfunction. $^{29,31,32}$ Recent health surveys conducted in Australia have concluded that although depression is a major health difficulty, which is highly prevalent in the community, the condition is often poorly recognised and under-treated. $^{22,23}$ Although the precise nature of the relationship between depression and sexual dysfunction is unclear, the significant correlations identified in the female Australian GSSAB cohort highlight the strong links between these conditions.

About one-half of all men and women in our study had taken no action with regards to seeking help or advice for their sexual difficulties and only $\sim 20 \%$ had consulted a medical doctor. The findings of the study indicate that many Australian men and women do not perceive sexual difficulties as significant or potentially treatable medical difficulties, or are not particularly bothered by them; this may be deterring them from raising the subject of their sexual functioning with their doctor. Furthermore, it seems that doctors in Australia rarely ask patients about their sexual health during a routine consultation, even though this would be welcomed by $\sim 40 \%$ of men and women. It is important that physicians initiate discussions about sexual health with their patients, and incorporate questions about sexual functioning into their routine patient work-ups. ${ }^{33}$

We conclude that middle-aged and older men and women in Australia continue to show sexual interest and activity, despite the presence of several sexual difficulties. Few of the individuals who experience such difficulties seek medical help, perhaps because they do not perceive their condition as sufficiently severe, potentially treatable, or sufficiently upsetting. Appropriate guidance from physicians and other healthcare professionals may encourage patients to discuss their sexual problems.

\section{Conflicts of interest}

Edson Moreira is a consultant for Pfizer. Dale B Glasser is employed by Pfizer Inc.; and has stock ownership or options (other than mutual funds) in Pfizer Inc. Rosie King works as a consultant for Pfizer. Fernanda Gross Duarte declares no conflict of interest. Clive Gingell works as a consultant for Pfizer. The Global Study of Sexual Attitudes and Behaviours was funded by Pfizer Inc.

\section{Acknowledgements}

The authors acknowledge the contribution of their colleagues on the study's international Advisory Board: Gerald Brock (Canada), Jacques Buvat (France), Uwe Hartmann (Germany), Sae-Chul Kim (Korea), Edward Laumann (USA), Bernard Levinson (South Africa), Ken Marumo (Japan), Alfredo Nicolosi (Italy) and Ferruh Simsek (Turkey).

\section{References}

1 Giuliano F, Chevret-Measson M, Tsatsaris A, Reitz C, Murino M, Thonneau P. Prevalence of erectile dysfunction in France: results of an epidemiological survey of a representative sample of 1004 men. Eur Urol 2002; 42: 382-9. doi: 10.1016/S0302-2838(02)00323-8

2 Helgason AR, Adolfsson J, Dickman P, Arver S, Fredrikson M, Göthberg $\mathrm{M}$, et al. Sexual desire, erection, orgasm and ejaculatory functions and their importance to elderly Swedish men: a populationbased study. Age Ageing 1996; 25: 285-91. doi: 10.1093/ageing/ 25.4.285

3 Dunn KM, Croft PR, Hackett GI. Sexual problems: a study of the prevalence and need for care in the general population. Fam Pract 1998; 15: 519-24. doi: 10.1093/fampra/15.6.519

4 Feldman HA, Goldstein I, Hatzichristou DG, Krane RJ, McKinlay JB. Impotence and its medical and psychosocial correlates: results of the Massachusetts Male Aging Study. J Urol 1994; 151: 54-61.

5 Laumann EO, Paik A, Rosen RC. Sexual dysfunction in the United States. Prevalence and predictors. JAMA 1999; 281: 537-44. doi: 10.1001/jama.281.6.537

6 Bacon CG, Mittleman MA, Kawachi I, Giovannucci E, Glasser DB, Rimm EB. Sexual function in men older than 50 years of age: results from the Health Professionals Follow-up Study. Ann Intern Med 2003; 139: 161-8.

7 Osborn M, Hawton K, Gath D. Sexual dysfunction among middleaged women in the community. BMJ 1988; 296: 959-62.

8 Barlow DH, Cardozo LD, Francis RM, Griffin M, Hart DM, Stephens $\mathrm{E}$, et al. Urogenital ageing and its effect on sexual health in older British women. Br J Obstet Gynaecol 1997; 104: 87-91.

9 Pinnock CB, Stapleton AMF, Marshall VR. Erectile dysfunction in the community: a prevalence study. Med J Aust 1999; 171: 353-7.

10 Najman JM, Dunne MP, Boyle FM, Cook MD, Purdie DM. Sexual dysfunction in the Australian population. Aust Fam Physician 2003; 32: 951-4.

11 Richters J, Grulich AE, de Visser RO, Smith AM, Rissel CE. Sex in Australia: sexual difficulties in a representative sample of adults. Aust N Z J Public Health 2003; 27: 164-70. doi: 10.1111/ j.1467-842X.2003.tb00804.x 
12 Minichiello V, Plummer D, Loxton D. Factors predicting sexual relationships in older people: An Australian study. Australas J Ageing 2004; 23: 125-30. doi: 10.1111/j.1741-6612.2004.00018.x

13 Minichiello V, Plummer D, Loxton D. Knowledge and beliefs of older Australians about sexuality and health. Australas J Ageing 2000; 19: $190-4$

14 Deacon S, Minichiello V, Plummer D. Sexuality and older people: revisiting the assumptions. Educ Gerontol 1995; 21: 497-513. doi: 10.1080/0360127950210509

15 Matthias RE, Lubben JE, Atchison KA, Schweitzer SO. Sexual activity and satisfaction among very old adults: results from a community-dwelling Medicare population survey. Gerontologist 1997; 37: 6-14.

16 Gott M, Hinchliff S. How important is sex in later life? The views of older people. Soc Sci Med 2003; 56: 1617-28. doi: 10.1016/ S0277-9536(02)00180-6

17 Nicolosi A, Laumann EO, Glasser DB, Moreira EDJr, Paik A, Gingell C. Sexual behaviour and sexual problems after the age of 40: the Global Study of Sexual Attitudes and Behaviors (GSSAB). Urology 2004; 64: 991-7. doi: 10.1016/j.urology.2004.06.055

18 Rosen RC. Assessment of female sexual dysfunction: review of validated methods. Fertil Steril 2002; 77: 89-93. doi: 10.1016/ S0015-0282(02)02966-7

19 Gardner MJ, Altman DG. Confidence intervals rather than P value: estimation rather than hypothesis testing. BMJ 1987; 292: 746-50.

20 ASCF principal investigators and their associates.. Analysis of sexual behaviour in France (ACSF). A comparison between two modes of investigation: telephone survey and face-to-face survey. AIDS 1992; 6 : 315-23.

21 Moynihan R. The making of a disease: female sexual dysfunction. BMJ 2003; 326: 45-7. doi: 10.1136/bmj.326.7379.45

22 Goldney RD, Fisher LJ, Dal Grande E, Taylor AW. Subsyndromal depression: prevalence, use of health services and quality of life in an Australian population. Soc Psychiatry Psychiatr Epidemiol 2004; 39: 293-8. doi: 10.1007/s00127-004-0745-5

23 Hawthorne G, Cheok F, Goldney R, Fisher L. The excess cost of depression in South Australia: a population-based study. Aust $N$ Z J Psychiatry 2003; 37: 362-73. doi: 10.1046/ j.1440-1614.2003.01189.x
24 White V, Hill D, Siahpush M, Bobevski I. How has the prevalence of cigarette smoking changed among Australian adults? Trends in smoking prevalence between 1980 and 2001. Tob Control 2003; 12: ii67-74.

25 Dunstan DW, Zimmet PZ, Welborn TA, De Courten MP, Cameron $\mathrm{AJ}$, Sicree RA, et al. The rising prevalence of diabetes and impaired glucose tolerance: the Australian Diabetes, Obesity and Lifestyle Study. Diabetes Care 2002; 25: 829-34. doi: 10.2337/ diacare.25.5.829

26 Kayigil O, Atahan O, Metin A. Multifactorial evaluation of diabetic erectile dysfunction. Int Urol Nephrol 1996; 28: 717-21. doi: 10.1007/ BF02552171

27 Dennerstein L, Alexander JL, Kotz K. The menopause and sexual functioning: a review of population-based studies. Annu Rev Sex Res 2003; 14: 64-82.

28 Gregorian RS, Golden KA, Bahce A, Goodman C, Kwong WJ, Khan ZM. Antidepressant-induced sexual dysfunction. Ann Pharmacother 2002; 36: 1577-89. doi: 10.1345/aph.1A195

29 Clayton AH, Pradko JF, Croft HA, Montano CB, Leadbetter RA, Bolden-Watson $\mathrm{C}$, et al. Prevalence of sexual dysfunction among newer antidepressants. $J$ Clin Psychiatry 2002; 63: 357-66.

30 Montgomery SA, Baldwin DS, Riley A. Antidepressant medications: a review of the evidence for drug-induced sexual dysfunction. $J$ Affect Disord 2002; 69: 119-40. doi: 10.1016/S0165-0327(01)00313-5

31 Hensley PL, Nurnberg HG. SSRI sexual dysfunction: a female perspective. J Sex Marital Ther 2002; 28: 143-53. doi: 10.1080/ 00926230252851267

$32 \mathrm{Hu}$ XH, Bull SA, Hunkeler EM, Ming E, Lee JY, Fireman B, et al. Incidence and duration of side effects and those rated as bothersome with selective serotonin reuptake inhibitor treatment for depression: patient report versus physician estimate. $J$ Clin Psychiatry 2004; 65: 959-65.

33 Sadovsky R. Integrating erectile dysfunction treatment into primary care practice. Am J Med 2000; 109: 22-8. doi: 10.1016/S0002-9343 (00)00657-4

Manuscript received 18 July 2007, accepted 7 February 2008 


\section{Appendix 1: Ascertainment of sexual difficulties}

Asked of every subject who had engaged in sexual intercourse (defined as any intimate behaviour including: penile-vaginal/anal intercourse, oral contact with genitals/breasts/nipples, or touching yours/other's genitals) during the previous 12 months.

During the last year have you ever experienced any of the following for a period of two months or more when you ... ? (PLEASE CHECK ALL THAT APPLY):

...lacked interest in having sex? [ ].

...were unable to reach climax? (experience orgasm) [ ].

... reached climax (experienced orgasm) too quickly? [ ].

... experienced physical pain during intercourse? [ ].

...did not find sex pleasurable? [ ].

...(MEN ONLY) had trouble achieving or maintaining an erection? [ ].

...(WOMEN ONLY) had trouble becoming adequately lubricated? [ ]. 